\title{
Kompetensi Sosial Guru dalam Mempersiapkan Masa Depan Siswa
}

\author{
Fitriyanti \\ E-mail: fi3yanti0801@gmail.com \\ Program Studi Pendidikan Bahasa dan Sastra Indonesia, Universitas Riau
}

\section{Pengantar}

Guru? Apa yang terlintas dipikiran kalian tentang seorang guru? Profesi sebagai seorang guru yang akrab dengan sebuah akronim bahasa Jawa yakni "sing digugu lan ditiru" yang artinya adalah orang yang dipercaya dan diikuti. Ini membuktikan bahwa seorang guru tidak hanya bertanggung jawab terhadap berkembangnya pengetahuan atau cerdasnya peserta didik dalam mata pelajaran, tetapi juga bertanggung jawab terhadap moral, etika, integritas serta karakter dari peserta didik. Oleh sebab itu, guru haruslah multitasking karena ada banyak kompetensi yang harus dikuasai seorang guru dimana masa depan generasi yang akan datang tergantung bagaimana kompetensi dari guru. Guru harus mempunyai kompetensi profesional yang sesuai dengan bidang tugasnya, sehingga guru memiliki integritas yang kuat dalam mengemban segala tugastugasnya. Dan kompetensi yang sangat penting yang harus dimiliki seorang guru adalah kompetensi sosial, karena menjadi seorang guru secara tidak langsung juga akan menjadi seorang motivator yang inspiratif dihadapan peserta didik.

\section{Kompetensi Sosial Seorang Guru}

Guru adalah sebuah profesi yang unik, karena menjadi seorang guru dituntut untuk mampu kompeten dalam banyak hal. Untuk menjadi guru profesional, ada beberapa kompetensi yang harus dikuasai oleh guru, yakni kompetensi pedagogik, kompetensi kepribadian, kompetensi sosial, dan kompetensi profesional. Dari keempat kompetensi yang harus dikuasai dan dimiliki oleh seorang guru, kompetesi sosial adalah kompetensi yang akan menghubungkan guru dengan lingkungan masyarakat, baik terhadap peserta didik maupun masyarakat luas.

Salah satu kompetensi yang harus dimiliki setiap guru adalah kompetensi sosial, yakni kemampuan mengelola hubungan kemasyarakatan yang membutuhkan berbagai 
keterampilan, kecakapan dan kapasitas dalam menyelesaikan masalah yang terjadi dalam hubungan antarpribadi (Boucher, 2012). Kegiatan pembelajaran tidak akan menarik jika seorang guru tidak mampu membantu siswanya memecahkan masalah yang dimilikinya, terutama dengan rasa ingin tahu siswa tentang informasi (Mustafa dan Zulhafizh, 2018). Guru berhubungan langsung dengan segala aspek dalam pendidikan yang sudah jelas mengharuskan terjadinya konteks sosial, salah satunya adalah dengan para stekholder sekolah yang masih memiliki keterkaitan dengan lingkungan sekolah. Dalam kompetensi sosial, guru juga berperan untuk membantu peserta didik dalam memecahkan masalah yang dihadapinya, dan hal ini membutuhkan komunikasi yang efektif baik dengan siswa maupun orang tua siswa.

Kompetensi sosial merupakan kemampuan guru sebagai bagian dari masyarakat (Mustafa dan Zulhafizh, 2017). Kompetensi sosial ini adalah wajah dari sifat dan sikap guru dimata masyarakat. Kompetensi sosial adalah kemampuan guru dalam berkomunikasi dan berinteraksi secara efektif dengan lingkungan sekolah maupun diluar lingkungan sekolah (Wibowo dan Hamrin, 2012). Menjadi seorang guru harus mampu membangun komunikasi yang baik dilingkungan sosial terlebih lagi di lingkungan sekolah yang mana guru harus memiliki kemampuan untuk berkomunikasi dengan baik terhadap sesama guru, peserta didik, dan kepala sekolah serta masyarakat lainnya.

\section{Pentingnya Kompetensi Sosial Guru untuk Persiapan Masa Depan Siswa}

Sebagai seorang guru yang memiliki peran besar dalam kemajuan sebuah negara, mencerdaskan anak bangsa dengan prestasi tanpa batas, berjiwa pemimpin, berakal kreatif dan berkarakter. Tentunya, masa depan peserta didik adalah segala sesuatu yang juga harus dipersiapkan oleh guru dan siswa itu sendiri. Ketika para siswa telah memasuki dunia kerja, baik di instansi pemerintahan, kantor layanan publik, menjadi pengusaha atau terjun ke dunia politik. Sebagai makhluk sosial mereka akan berinteraksi dengan orang lain dan akan menimbulkan terjadinya konteks sosial.

Setiap peserta didik khususnya di jenjang sekolah menengah, mereka harus dipersiapkan dengan berbagai kompetensi sosial melalui program yang terdesain baik, dapat dievalusi dan terukur. Mustafa dan Zulhafizh (2018) seorang guru harus 
mengambil tindakan terbaik untuk siswanya. Ia dapat memotivasi siswanya untuk menjadi pribadi yang baik.

Han dan Kristen (2006) mengatakan kompetensi sosial dikonseptualisasikan terdiri dari enam kategori kompetensi sosial yang harus dilatih guru terhadap siswanya, yang bertujuan mempersiapkan siswa dalam menghadapi tantangan yang berkaitan dengan kehidupan sosial dan komunikasi di masa depan. Keenam kategori atau aspek tersebut adalah sebagai berikut:

1. Self-regulation (regulasi diri), guru perlu melatih siswa dalam mengelola emosi, agar mampu melakukan interaksi sosial dengan teman sebaya. Jika terdapat siswa yang bersikap impuls (bertindak berdasarkan insting dan tidak pada logika), maka harus dilatih agar lebih bersikap tenang dan mampu mengontrol emosi, sehingga dapat mengambil keputusan dan bertindak secara rasional.

2. Adoption social values (penerapan atau adopsi nilai-nilai sosial), berkaitan degan hal ini siswa harus diajarkan untuk bisa menerapkan nulai-nilai sosial seperti sikap saling peduli, tanggung jawab, kejujuran, tolong-menolong dan fleksibilitas dalam menerapkan tindakan-tindakan sosial.

3. Positive self-identity (identitas diri yang positif), pada aspek ini siswa dilatih mengenai kebaikan dalam dirinya sehingga akan terbentuknya identitas yang positif yang akan mampu meningkatkan efektifitas hubungan sosial dengan orang lain. Mereka yang memiliki identitas diri yang positif seperti personal power, sense of competence dan harga diri yang baik, akan menjalin hubungan dan menularkan kebaikan terhadap orang lain.

4. Interpersonal knowladge and skills (pengetahuan dan keterampilan interpersolan), kompetensi ini mencakup memahami kebutuhan dan perasaan orang lain, mengrtikulsi gagasan memecahkan masalah, bekerja sama dan bernegosiasi. Siswa dilatih untuk menyesuaikan sikap dengan kondisi, juga mengutarakan perasaannya.

5. Cultural competence (kompetensi budaya), para siswa harus dilatih untuk meningkatkan pengetahuan dan pemahaman terhadap respek orang lain dan kemampuan secara efektif dan nyaman saat berkomunikasi dengan orang yang berbeda ras, agama, etnik, dan budaya. Mereka diajarkan untuk saling menhormati dan toleransi 
6. Planning and decision skills (keterampilan perencanaan dan pengambilan keputusan), kemampuan untuk bertindak dengan cara yang terarah, dengan membuat pilihan, mengembangkan rencana, mencari solusi dari permasalahan yang terjadi, melakukan tindakan positif untuk mencapai tujuan.

\section{Penutup}

Kompetensi sosial adalah salah satu kompetensi yang harus dimiliki setiap guru, yakni kemampuan mengelola hubungan kemasyarakatan yang membutuhkan berbagai keterampilan, kecakapan dan kapasitas dalam menyelesaikan masalah yang terjadi dalam relasi sosial. Menjadi seorang guru harus mampu membangun komunikasi yang baik dilingkungan sosial terlebih lagi di lingkungan sekolah. Guru sebagai laskar pendidikan sehingga kehadiran guru yang memilki kompetensi sosial yang baik adalah hal yang diimpikan oleh peserta didik, terlebih lagi untuk mereka mempersiapkan masa depan cemerlang sebagai generasi yang cerdas dan menginspirasi.

\section{Referensi}

Boucher, Michelle Dawn. (2012). Social Competence Education for Pre-Service Teachers. California State University: Scacramento.

Han, Heejeoung Sophia, \& Kristen Mary Kemple. (2006). Components of Social Competence and Strategies of Support: Considering What to Teach and How. Early Childhood Education Journal, 34 (2), 241-246.

Mustafa, M. N., \& Zulhafizh. (2017). Building the Proffessionalism of Teachers as an Effort to Improve Education. In Husein, R, et al (Eds), (p.449). Medan.

Mustafa, M. N., \& Zulhafizh. (2018). Information Mastery by Teachers as a Strategy to Succeed in the Implementation of Teaching and Learning Activities. In International Seminar and Annual Meeting BKS-PTN Wilayah Barat 2018 (pp.516-523), Palembang.

Wobowo, Agus \& Hamrin. (2012). Menjadi Guru Berkarakter Strategi Membangun Kompetensi \& Karakter Guru. Yogyakarta: Pustaka Pelajar. 


\section{*Data Penulis}

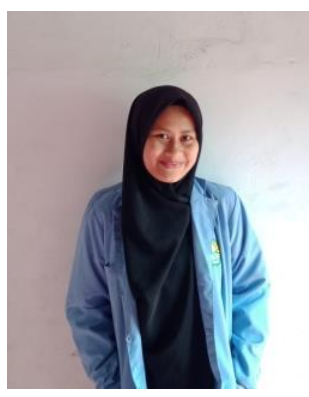

Fitriyanti, lahir di Tanjung Kapal, 8 Januari 2001. Pada tahun akademik 2017-2018, ia melanjutkan studi pada strata satu Jurusan Pendidikan Bahasa dan Seni di Program Studi Pendidikan Bahasa dan Sastra Indonesia FKIP Universitas Riau melalui jalur SNMPTN (Seleksi Nasional Masuk Perguruan Tinggi Negeri), hingga saat ini masih berstatus sebagai mahasiswi.

Beberapa karya tulisan fiksinya berbentuk antologi diantaranya, Sangkala (antologi cerpen), Kursi Tak Bermeja (antologi cerpen), 8 Semanggi (antologi puisi stanza), Taman Jenaka (antologi fabel) dan The Greatest Gift (antologi cerpen).

Kontak:

Hp/WA $\quad:+6282386250400$

Email : fi3yanti0801@gmail.com 